\title{
Strategies for Working with Digital Medical Images
}

\author{
SWETA SNEHA \\ Computer Information Systems \\ Georgia State University \\ ssneha@cis.gsu.edu
}

\author{
ALINA DuLIPOVICI \\ Computer Information Systems \\ Georgia State University \\ adulipovici@cis.gsu.edu
}

\begin{abstract}
Medical images are a critical component of the healthcare system with great impact on the society's welfare. Traditionally medical images were stored on film but the advances in modern imaging modalities made it possible to store them electronically. Thus, this research proposes a novel framework for classifying various strategies for storing, retrieving and processing digital medical images. In addition to a detailed discussion, the assessment of the classification framework includes a potential usage scenario of the framework. For researchers, this study identifies important strategies and points out future research directions while, for practitioners, the proposed framework might help medical users develop a lucid understanding of the different approaches and their advantages and disadvantages.
\end{abstract}

\section{Introduction}

Healthcare is an important constituent of modern societies, representing a large percentage of GDP, and sustaining a high political profile and a strong public interest [11]. In this context, medical images are an ever increasing component. Traditionally medical images were stored on film but the advances in modern imaging modalities made it possible to store them electronically. Nowadays, medical images are generated in digital form and stored in large medical Picture Archive and Communication Systems (PACS).

Given that digital medical images represent enormous amount of data, electronic resources for processing and for intelligent indexing are in great need. For example, the total amount of storage for medical images produced by the department of radiology at a typical hospital in USA could be in the upwards of 10 Terabytes and the total amount of digital medical images produced in USA could be in the order of thousands of Petabytes. Even though these medical images are mostly coming from a digital source, a large proportion of the images are not archived in the long run [38]. Hence, some of the challenges faced by the health care sector with respect to medical images include:

- Storage and archival of large amount of medical images for future access / research;

- Standards for sharing medical images of patients for consultation or second opinion;

- Performing complex computation and analysis over large datasets of a certain kind of medical images (e.g. all the mammograms of patients between $20-30$ years of age);

- Secure exchange of patient's medical images between remote locations;

- Efficient retrieval of medical images based on standard queries.

Given this context, this research addresses an important research question: How can mechanisms for storage, access and retrieval of digital medical images be improved? This question is tackled in two phases. Firstly, as the number of medical images in specialized medical repositories continues to grow, so do the methods to access and process image content-based files from medical repositories. It is thus essential to begin with an assessment of the strategies used by researchers and by practitioners for handling digital medical images. Secondly, a detailed analysis of the resulting classification framework identifies benefits and limitations of the current strategies. Based on this analysis, this research proposes other solutions that have great potential for improving mechanisms for storage, access and retrieval of digital medical images.

The contributions of this research are threefold. First, it provides an evaluation of the myriad of methods for storage, access and retrieval of digital medical images. Second, it provides clear guidelines for future research in this field with regard to the use of emergent technologies such as grid services and semantic web. Third, the classification framework offers a well-structured view of the different challenges raised by processing medical images.

The next section of this research describes the methodology and the three main strategies that compose 
the classification framework. The third section validates the framework by using three approaches: an analysis based on complexity, development and implementation costs and benefits; a usage scenario; and identification of new strategies for future research. Finally, the fourth section puts forward some concluding remarks.

\section{A Framework for Identifying Strategies}

The first phase of this study consists of an interpretive analysis of the literature on medical images. Relevant scholarly manuscripts published between 1996 and 2005 were selected using library resources such as ABI Inform, the Web of Science database, and Google Scholar. It is necessary to add that the authors of the present research did not try to classify in a framework all the articles and the books found. Instead, an exploratory approach was used to build a categorization scheme from the selected literature. The final sample of relevant exemplars included seventeen articles from thirteen conference proceedings, and thirteen articles published in eleven refereed journals (Appendix A).

For creating the framework, the authors used a morphological analysis, which is "a technique for building structures (morphologies) of existing information in a subject area" [20, p. 76]. Conducting a morphological analysis implies that first, relevant literature is examined so that known classification dimensions can surface. Thus three main strategies (figure 1) emerged based on the technological approaches used in the selected literature. The following sections discuss each of these strategies.

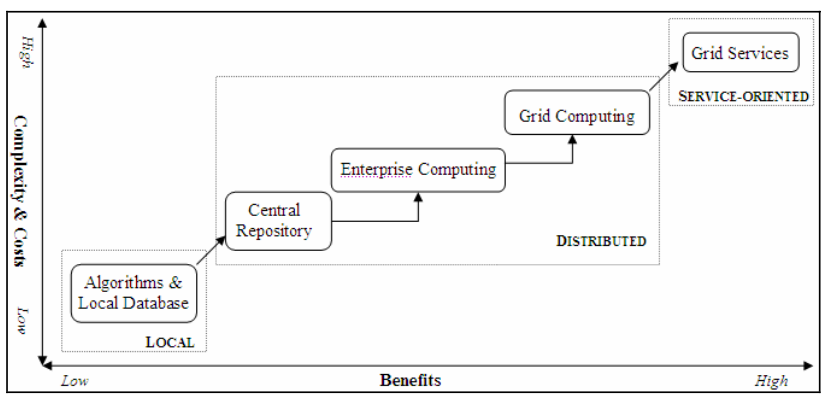

Figure 1: Classification Framework

\subsection{Strategy 1: Local Systems}

The local systems strategy is defined by the usage of local image-databases and applications, which on specialized algorithms for content-based image retrieval and processing (Table 1). With regard to the medical image format, the DICOM (Digital Image and COmmunication in Medicine) standard has emerged as a widely accepted norm $[15,45]$. The DICOM file format contains one or several image slices as well as metadata relative to the patient (e.g. name, sex, age, hospital, etc.) and to the image (e.g. image acquisition date, acquisition device, parameters, etc.). The majority of the most recent applications working with medical images file conform to the DICOM 3.0 standard [13].

Table 1: Medical image projects using local systems

\begin{tabular}{|l|l|l|}
\hline Type of project & \multicolumn{1}{|c|}{ Description } & Reference \\
\hline $\begin{array}{l}\text { Object-oriented } \\
\text { algorithms }\end{array}$ & $\begin{array}{l}\text { Prototype for multimodality } \\
\text { image analysis in the fields } \\
\text { of radiological analysis, } \\
\text { neurosurgery planning, and } \\
\text { radiation therapy planning }\end{array}$ & {$[16]$} \\
\hline $\begin{array}{l}\text { Algorithm } \\
\text { based on JPEG } \\
\text { standard }\end{array}$ & $\begin{array}{l}\text { Algorithm for combining } \\
\text { patient information text and } \\
\text { graphical documents. }\end{array}$ & {$[46]$} \\
\hline $\begin{array}{l}\text { Electronic } \\
\text { cleansing } \\
\text { algorithm }\end{array}$ & $\begin{array}{l}\text { Prototype for 3D views of } \\
\text { the colon based on CT } \\
\text { scans. }\end{array}$ & {$[32]$} \\
\hline $\begin{array}{l}\text { Algorithms } \\
\text { based on finite- } \\
\text { element } \\
\text { modeling and } \\
\text { deformable } \\
\text { model-based } \\
\text { method }\end{array}$ & $\begin{array}{l}\text { Prototype for 3D modeling } \\
\text { and analysis of changes in } \\
\text { the shape and motion of the } \\
\text { heart from MRI-tagged } \\
\text { data. }\end{array}$ & {$[44]$} \\
\hline $\begin{array}{l}\text { Reference data } \\
\text { set }\end{array}$ & $\begin{array}{l}\text { Prototype for a medical } \\
\text { image database to be used } \\
\text { for medical training. }\end{array}$ & {$[40]$} \\
\hline
\end{tabular}

Local systems were a de facto solution in the ' 80 , but they still find devotees in low-budget projects. Although the algorithms are highly complex and require great expertise, a local system strategy is considered less complex than the other strategies, while still offering good performance results for content-based medical queries [40]. The limitation is obviously the dependence on the local machine and, consequently, the inability to share these computational resources among distributed users. However, the image-databases used for this strategy can easily be converted for a Web access [40].

\subsection{Strategy 2: Distributed Systems}

The distributed strategy relies on the use of distributed systems, which are systems situated in multiple locations throughout an organization and working in a cooperative manner. Depending on the type of distributed systems, the review of the medical literature identified three substrategies: central repository (Table 2), enterprise computing system (Table 3), and grid computing technologies (Table 4). The following paragraphs discuss briefly each of these sub-strategies.

The high popularity of the World Wide Web and recent improvements in high-speed intranets have guaranteed the main conditions for creating large databases containing medical images that users can access via a web Interface 
(Table 2). Thus, the central repository sub-strategy implies access to and use of medical images stored in an online central repository. Such solutions provide synchronous collaboration at reasonable costs and simultaneous access to medical images [23]. The implementation process is fairly simple and it also includes standard SQL queries allowing doctors to retrieve relevant medical images.

Table 2: Medical image projects using a central repository

\begin{tabular}{|l|l|l|}
\hline Type of project & \multicolumn{1}{|c|}{ Description } & Reference \\
\hline DICOM DBMS & $\begin{array}{l}\text { Image-database system } \\
\text { managing medical images } \\
\text { and their image-attributes, } \\
\text { both for research and clinical } \\
\text { purposes. The database is } \\
\text { accessed from workstations } \\
\text { located near the users in } \\
\text { offices, laboratories, and } \\
\text { operating rooms. }\end{array}$ & [41] \\
\hline DICOM DBMS & $\begin{array}{l}\text { Information system for } \\
\text { cooperative medical imaging } \\
\text { diagnosis facilities among } \\
\text { remote medical users and } \\
\text { cooperative decision support. }\end{array}$ & {$[23]$} \\
\hline $\begin{array}{l}\text { Dermatological } \\
\text { Online Atlas }\end{array}$ & $\begin{array}{l}\text { Image database on the World } \\
\text { Wide Web containing about } \\
\text { 3,000 clinical images } \\
\text { covering more than 600 } \\
\text { dermatological diagnoses }\end{array}$ & {$[14]$} \\
\hline $\begin{array}{l}\text { Based on the } \\
\text { Visible Human } \\
\text { project data }\end{array}$ & $\begin{array}{l}\text { Open source image } \\
\text { processing project for } \\
\text { analyzing the head and neck } \\
\text { anatomy of the Visible } \\
\text { Human Project data. }\end{array}$ & [52] \\
\hline
\end{tabular}

Consulting images from similar cases helps doctors with the diagnosing but not without some problems. First, a web interface to a central repository provides no automated analysis of the images. Second, it does not provide an integrated approach for coordinating the use of resources across multiple sites [19]. Third, although the medical images conform to the DICOM standard, the queries are not necessarily efficient and hence a fairly large number of results may result (i.e. similar to the "Google effect"). Overcoming these problems means adopting the other types of distributed systems.

The introduction of web browsers has certainly made distributing images easier, but the true challenge lies in integrating distributed heterogeneous applications that share semi-structured data. Thus, the second sub-strategy of distributed systems is defined by the usage of enterprise computing systems (e.g. CORBA, DCOM or Enterprise Java Beans) [19]. In the medical image literature, one article was identified that used a CORBA object-based architecture (Table 3).
Table 3: Medical image projects using enterprise computing

\begin{tabular}{|l|l|l|}
\hline \multicolumn{1}{|c|}{$\begin{array}{c}\text { Type of } \\
\text { project }\end{array}$} & \multicolumn{1}{|c|}{ Description } & Reference \\
\hline $\begin{array}{l}\text { CORBA } \\
\text { architecture }\end{array}$ & $\begin{array}{l}\text { CORBA-based architecture based } \\
\text { on DICOM standard for a } \\
\text { teleradiology system. }\end{array}$ & {$[34]$} \\
\hline $\begin{array}{l}\text { Security } \\
\text { middleware }\end{array}$ & $\begin{array}{l}\text { Security middleware for DICOM } \\
\text { images that offers access control, } \\
\text { policy management, } \\
\text { demographics filtering, and log } \\
\text { maintenance, constrained to the } \\
\text { Canadian-Manitoban PHIA and } \\
\text { the DICOM standard. }\end{array}$ & {$[31]$} \\
\hline
\end{tabular}

CORBA (Common Object Request Broker Architecture) is a platform-independent architecture and infrastructure proposed by the Object Management Group (www.omg.org) for integrating various applications in computer networks. Using standard protocols, a CORBAbased program interoperates with another CORBA-based program existing on another computer. This kind of architecture enables access to a much larger user base than in the case of a local system or a platform-dependent approach. Enterprise computing systems provide standard resource interface, remote invocation mechanisms and trading services for knowledge discovery, hence making it easier to share resources within the organization. For the healthcare industry, the most important advantage is that medical images can be stored on local or remote image servers and consequently, information for a particular patient can be gathered from different sources (e.g. hospitals, medical centers, medical laboratories, etc.).

However, using enterprise computing architectures raises some issues as well. The first one is related to security concerns although researchers have advanced some interesting solutions [31]. The second one is about the client-server type of interaction, which has limited abilities for coordinating multiple resources [19]. The third one, and the most important for processing medical images, is with regard to the limitations of the CORBA architecture when substantial computational resources are needed [7, 42].

The third sub-strategy identified in the review of medical distributed systems is defined by the use of grid computing technologies. The term "grid" was introduced in the Software Engineering literature in the mid 90's [19]. The initial definition of grid computing has since evolved in order to better incorporate recent progress. Thus, the concept of grid computing is currently defined as "coordinated resource sharing and problem solving in dynamic, multi-institutional virtual organizations" [19].

From a practitioner's perspective, grid computing is seen as a new approach for distributed computing that 
combines benefits from distributed systems, parallel computing systems, peer-to-peer computing, and cluster management systems However, grid technologies are concerned not only with file exchange, but also with access to resources such as computers, software and data in a highly controlled setting where both users and providers clearly define what is shared, who is allowed to access it and under what conditions [19]. Given these characteristics, grid technologies create dynamic and secure environments for computing and storing resources.

In the medical literature review, five research projects using grid computing were identified (Table 4). It is interesting to note that some of the projects were evolutions of older projects (e.g. Visible Human Project), while others evolved into even more complex projects (e.g. TacWeb).

Table 4: Grid computing and Medical Images

\begin{tabular}{|l|l|l|}
\hline \multicolumn{1}{|c|}{$\begin{array}{c}\text { Project } \\
\text { Name }\end{array}$} & \multicolumn{1}{|c|}{ Description } & Reference \\
\hline TacWeb & $\begin{array}{l}\text { Grid Portal for Electronic Patient } \\
\text { Record including medical images }\end{array}$ & {$[2]$} \\
\hline DataGrid & $\begin{array}{l}\text { Proof of concept of a biomedical } \\
\text { grid }\end{array}$ & $\begin{array}{l}{[9] ;[8] ;} \\
{[15] ;[38]}\end{array}$ \\
\hline- & $\begin{array}{l}\text { Description of a grid } \\
\text { environment in the University } \\
\text { Hospitals of Geneva }\end{array}$ & {$[39]$} \\
\hline eDiaMoND & $\begin{array}{l}\text { Description of a Grid-enabled } \\
\text { medical imaging relational } \\
\text { database for DICOM files. }\end{array}$ & {$[45]$} \\
\hline $\begin{array}{l}\text { Visible } \\
\text { Human } \\
\text { Project }\end{array}$ & $\begin{array}{l}\text { Description of the project and its } \\
\text { benefits for medical training. }\end{array}$ & {$[25] ;[29]$} \\
\hline
\end{tabular}

These results are consistent with the enormous potential that grid technologies present for content-based image retrieval, text mining, and 3D \& 4D image processing. For example, in the University Hospitals of Geneva there are more than 5400 computers, which are used only 5$10 \%$ of the time [39]. The idea of grid computing is to couple all these computational resources and to use them in a more efficient way. The attached benefits translate into an improvement of the quality of the data, a decrease in development costs for integrating data and an efficient sharing of patient-related information [39]. The challenge on the other hand is that of interoperability due to differences in data formats and proprietary applications. Traditional medical systems are generally a collection of multiple applications sharing at best semi-structured data. Hence, maintenance and upgrading are costly and difficult. While distributed object computing such as CORBA or grid technologies solve some of the problem, it is not the solution for every application integration job. The distributed and heterogeneous nature of today's healthcare systems inevitably requires more complex solutions.

\subsection{Strategy 3: Service-oriented systems}

This strategy is founded on a different paradigm, namely a service-oriented paradigm that shifts the focus from the traditional standalone-hosting model to a networkhosting. Currently, the only example (i.e. sub-strategy) found in the medical literature uses grid services, a technology that emerged from the application of web services technologies to the grid computing technologies. As the previous section has already described the grid computing, this section concentrates on the web services and on the integration of these two technologies.

Similarly to grid technologies, Web services also operate in a controlled setting where users and providers negotiate the quality of the service they expect to receive / offer. Specifically, Web services are software applications that provide an interface through which other programs can gain access [33]. By offering a language-neutral, environment-neutral programming model, they integrate heterogeneous products to homogeneous componentbased solutions [24, 49]. This integration is based on the architectural concepts of OO middleware as well as on commonly accepted standards such as XML and Internet protocols (HTTP, TCP/IP) [33, 49].

Table 5: Grid Services and Medical Images

\begin{tabular}{|c|c|c|}
\hline Project Name & Description & Reference \\
\hline TacWeb & $\begin{array}{l}\text { A Grid Portal for Electronic } \\
\text { Patient Record including } \\
\text { medical images }\end{array}$ & {$[1]$} \\
\hline MammoGrid & $\begin{array}{l}\text { The MamoGrid prototype } \\
\text { offers a high-quality clinician } \\
\text { visualization workstation for } \\
\text { data acquisition and } \\
\text { inspection, a DICOM interface } \\
\text { for various medical services } \\
\text { (annotation, security, image } \\
\text { analysis, data storage and } \\
\text { querying services) and secure } \\
\text { access to the grid service } \\
\text { network. }\end{array}$ & $\begin{array}{l}{[4] ;[3] ;} \\
{[17] ;[47]}\end{array}$ \\
\hline GEMSS & $\begin{array}{l}\text { Prototype for maxillo-facial } \\
\text { surgery simulation, neuro- } \\
\text { surgery support, radio-surgery } \\
\text { planning, inhaled drug- } \\
\text { delivery simulation, } \\
\text { cardiovascular simulation and } \\
\text { tomographic image } \\
\text { reconstruction. }\end{array}$ & $\begin{array}{l}{[5] ;[26] ;} \\
{[30]}\end{array}$ \\
\hline $\begin{array}{l}\text { HealthInfo } \\
\text { Grid }\end{array}$ & $\begin{array}{l}\text { A general health information } \\
\text { Grid middleware that tackles } \\
\text { legacy system integration, } \\
\text { maintainability, security and } \\
\text { privacy. }\end{array}$ & {$[6]$} \\
\hline
\end{tabular}


In a grid service medical context, a medical user employs a Web interface or a local application to access a service via a provider's portal or server. In this way, medical practitioners can obtain and, most importantly, analyse medical images without expensive investments in hardware infrastructure and software engineers' expertise. They do however need to pay a pre-negociated price per use [5]. Advanced simulation and medical images processing services for virtual prototyping, planning medical interventions, therapeutic protocols, inhaled drug delivery simulation, or near real-time surgical support are some of the applications from which doctors and their patients can benefit (Table 5). Hence, in a secure environment, medical grid services target to offer patients a non-invasive but complete and correct diagnosis.

\section{Assessment of Strategies}

Validating a classification framework is generally a difficult endeavour. A small exercise in this sense would be to use the next published article on medical images and evaluate its position in the framework. Over time, future research will reject or prove the accuracy of the proposed framework. As the literature on this topic is extremely fragmented and mainly published in conference proceedings or small-audience journals that are difficult to obtain, it is impossible - albeit highly desirable - to try to populate the framework and then validate it by verifying the necessary condition and the sufficiency condition [50]. Nevertheless, useful conclusions can be drawn from this classification framework.

An evolutionary process can be noticed when examining the framework from a higher level perspective. On the one hand, given recent technological advancement, practitioners can embrace more sophisticated approaches. On the other hand, they seek better solutions, which effectively address the challenges that emerge when building scalable and interoperable approaches [19]. Thus, some of the strategies build on previous strategies, whereas others amalgamate elements from different strategies and even from different disciplines. For instance, the use of complex algorithms was a stand-alone method in the 80', but then it became a basic element in more complex solutions such as enterprise solutions or even grid services. The use of DICOM-format databases is another example of an element that is used in several sub-strategies.

With the adoption of Internet, accessing medical images via web-enabled technologies was a major improvement over the local systems and brought great benefits by providing faster and more accurate patient care, and by decreasing development and implementation costs from storing, retrieving and analysing digital medical images [34]. The enterprise computing systems (e.g. CORBA) extended the benefits from the use of a central repository sub-strategy by adding an Internet based viewer program that, in same cases, allowed complex image analysis [34]. Compared to enterprise computing, grid computing and grid services tackle critical issues such as secure interoperability and offer a richer interface definition language [18]. Moreover grid services, as an extension to web services, are dynamic, time-limited and stateful instances with delegated authentication credentials [18].

An evaluation of the various strategies based on the previous literature review is presented in Table 6 . The strategies are assessed on the dimensions of benefits, complexity, and development and implementation costs.

Table 6: Evaluation of Strategies

\begin{tabular}{|c|c|c|}
\hline $\begin{array}{l}\text { Strategy } \\
\text { Name }\end{array}$ & $\begin{array}{l}\text { Benefits, Costs and } \\
\text { Complexity }\end{array}$ & Limitations \\
\hline $\begin{array}{l}\text { Local } \\
\text { Systems }\end{array}$ & $\begin{array}{l}\text { - Less complex but still } \\
\text { good performance } \\
\text { results for content- } \\
\text { based medical queries } \\
{[40]}\end{array}$ & $\begin{array}{l}\text { - Dependence on } \\
\text { local machine; } \\
\text { - Inability to share } \\
\text { resources if } \\
\text { distributed users } \\
\text { [40] }\end{array}$ \\
\hline $\begin{array}{l}\text { Central } \\
\text { Repository }\end{array}$ & $\begin{array}{l}\text { - Simultaneous access } \\
\text { to medical images; } \\
\text { - Synchronous } \\
\text { collaboration among } \\
\text { distributed users [23]; } \\
\text { - Fairly simple process } \\
\text { with reasonable } \\
\text { development cost; } \\
\text { - Standard SQL queries } \\
\text { for image retrieval. }\end{array}$ & $\begin{array}{l}\text { - No automated } \\
\text { analysis of the } \\
\text { images; } \\
\text { - No integrated } \\
\text { approach to } \\
\text { coordinate } \\
\text { resources across } \\
\text { multiple sites } \\
\text { [19]; } \\
\text { - Possible to use } \\
\text { inefficient SQL } \\
\text { queries (large } \\
\text { number of } \\
\text { results). }\end{array}$ \\
\hline $\begin{array}{l}\text { Enterprise } \\
\text { Computing }\end{array}$ & $\begin{array}{l}\text { - Standard resource } \\
\text { interface; } \\
\text { - Remote invocation } \\
\text { mechanism and } \\
\text { trading services for } \\
\text { knowledge discovery; } \\
\text { - Resource sharing } \\
\text { within the } \\
\text { organization. }\end{array}$ & $\begin{array}{l}\text { - Security } \\
\text { concerns; } \\
\text { - Limited abilities } \\
\text { for coordinating } \\
\text { multiple } \\
\text { resources [19]; } \\
\text { - Substantial } \\
\text { computing } \\
\text { resources } \\
\text { required for } \\
\text { medical images } \\
\text { processing }\end{array}$ \\
\hline $\begin{array}{l}\text { Grid } \\
\text { Computing }\end{array}$ & $\begin{array}{l}\text { - Dynamic environment } \\
\text { for data exchange and } \\
\text { resource sharing in } \\
\text { multi-institutional } \\
\text { virtual organizations; } \\
\text { - Secure environment } \\
\text { [19]; } \\
\text { - Improved quality of } \\
\text { data; } \\
\text { - Lower development } \\
\text { costs for integrating } \\
\text { data and efficient }\end{array}$ & $\begin{array}{l}\text { - Interoperability } \\
\text { due to } \\
\text { differences in } \\
\text { data formats; } \\
\text { - Sharing of } \\
\text { proprietary } \\
\text { applications; } \\
\text { - High } \\
\text { implementation } \\
\text { costs and } \\
\text { complexity. }\end{array}$ \\
\hline
\end{tabular}




\begin{tabular}{|l|l|l|}
\hline & sharing [39] & \\
\hline Grid & $-\begin{array}{l}\text { Secure } \\
\text { interoperability; }\end{array}$ & - Higher \\
Services & $-\begin{array}{l}\text { Lower investments in } \\
\text { hardware and } \\
\text { software [18] }\end{array}$ & \\
& & \\
\hline
\end{tabular}

Based on the evaluations outlined in Table 6 , figure 2 graphically compares the strategies on the aforementioned dimensions (complexity, potential benefits, and development and implementation costs). Obviously the Ideal Strategy (see "IS" circle in figure 2) has high benefits, low costs and a low level of complexity. This graphical representation does not indicate that one strategy is better than another: each has its advantages and disadvantages. Given the characteristics of a specific context, a healthcare organization may emphasize more a specific dimension. Nonetheless, this graph can potentially be used for selecting and for justifying a particular strategy.

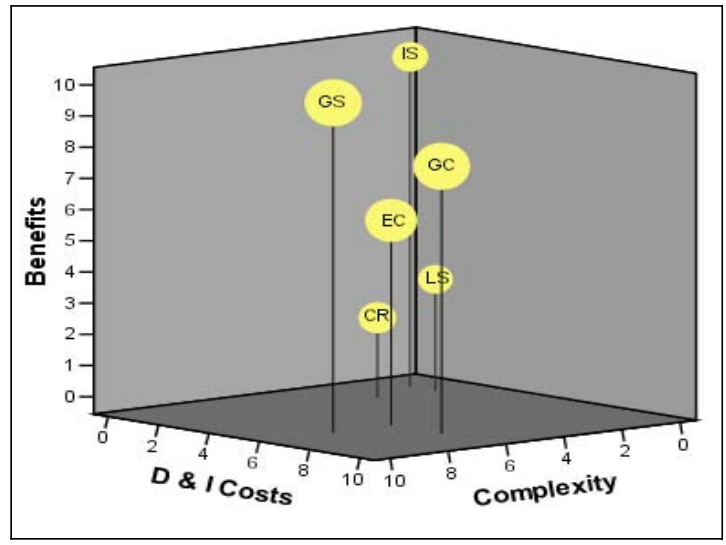

$$
\begin{array}{ll}
\mathbf{L S}=\text { Local System } & \mathbf{G C}=\text { Grid Computing } \\
\mathbf{C R}=\text { Central Repository } & \mathbf{G S}=\text { Grid Services } \\
\mathbf{E C}=\text { Enterprise Computing } & \text { IS }=\text { Ideal Strategy }
\end{array}
$$

Figure 2: Assessment of various strategies for medical images

Another interesting aspect that emerged from the classification framework is that its setting does not seem to matter that much. Indeed settings having little communality with the medical field have used the same technologies. This leads us to believe that the healthcare area is not that technologically unique as some researchers claim [36]. Hence, it would be interesting to try, in the context of medical applications, technologies used in other areas. However, researchers should proceed carefully as another explanation is possible as well: although there is no individual characteristic that is particularly unique to processing medical images, the collection of characteristics is unique and might involve some specific adjustments.
In terms of research methodology, most of the papers examined fall under the paradigm of design research [27]. Their authors focus mainly on building a prototype. Although an important number of papers are published in practitioner-oriented conference proceedings, it does not weaken the research framework. On the one hand, the research design might not be highly rigorous, but on the other hand, we need to consider that these prototypes have been developed in computer science schools, in multidisciplinary teams, or in European research projects and in these contexts conferences are seen as being more prestigious. However not all the proposed prototypes are validated (e.g. [6, 34, 39, 45]). A few articles used experiments to compare the effectiveness of their prototype with other existing tools (e.g. [16, 28, 32, 46]) in the spirit of Hevner et al.'s [27] guidelines who advocate objectiveness and rigour in design research.

Finally, it is worth noting that most of the recent research has focused on grid services. While it is not surprising because this strategy seems to offer the most benefits, it is deplorable that not all these papers provide a "Related work" section that positions their contribution relative to the existing literature. Therefore, it is highly desirable that researchers and practitioners use the framework not only for identifying novel and diverse avenues for extending research on grid services, but also for positioning their contributions. The following section describes the use of the framework in a typical usage scenario.

\subsection{A Typical Usage Scenario for Choosing a Strategy}

The classification framework (figure 1) proposed in the current research along with the graphical comparison of the strategies proposed (figure 2) have the potential of being used to determine which strategy best suits a given situation. The following usage scenario provides a "proofof-concept". In the case of a hypothetical hospital (Hospital ABC), the framework and its graphical representation were useful in determining a strategy for the hospital with regards to handling digital medical images given the current requirements and constraints.

\section{$>$ Scenario Context}

Hospital $\mathrm{ABC}$ is going through a phase of restructuring. Currently the hospital stores its digital images on a local database, which can be queried within the perimeter of the hospital to retrieve images. Automatic analysis of the images is done by the technological expertise at the hospital. The hospital was started a few years back and it has expanded a lot since then. It opened sister branches and has also made partnerships with other healthcare facilities in the neighbourhood. When the hospital became operational, the founders had not anticipated the phenomenal rise in the number of patients and 
consequently an increase in the number and size of digital images produced, stored and analyzed. To make matters worse, some of the doctors and patients were visiting more than one hospital. For instance: a patient, P1, has prior mammography images at hospital $\mathrm{ABC}$ and she visited hospital $\mathrm{XYZ}$ to see a doctor who is associated with both the facilities. If the doctor wants to consult the prior images with the latest images to see the changes then he will either have to get somebody to send him the digital images in an attachment or get patient P1 to carry the paper films with her when going in between the two facilities. This was increasing the work load of the staff and also creating unnecessary duplication of paper films. Furthermore, there was no way to promote collaborative, complex analysis of the images or share the computational resources across multiple sites. This increased administrative costs along with reducing the productivity and efficiency of the hospital resources.

\section{$>$ Use of the framework}

The requirements as outlined by the major stakeholders were to create a system which would:

- Promote resource sharing of data, storage, network, applications etc. which means, that the digital images in one hospital could be accessed and analysed by doctors at another hospital seamlessly.

- Provide maximum level of security, by defining who is allowed to access what resources and under what conditions.

- Promote collaborative, complex analysis of digital images by doctors separated by time and distance.

- Provide a solution that increase efficiency and productivity of the hospital resource doctors.

Supposing that the system was funded by the hospitals together, cost was not the main constraint as long as the system was not very complex to handle and maintain on a day to day basis. Hence the high level requirement was to identify a strategy that could best meet the aforesaid requirements without adding too much complexity in the process. This required a two-step approach where the first step entails an assessment of various strategies that are utilized for handling digital medical images and identifying strategies that could potentially be implemented to meet the aforementioned requirements and constraints. The second step involves in depth evaluation of each strategy to identify the one that would best meet the expectations set forth by the stakeholders.

The classification framework (figure 1) categorizes the various strategies that have been employed by researchers and practitioners to deal with digital medical images and classifies them based on the characteristic of the technology; local systems, distributed systems and service oriented systems. The classification also shows the progression from low to high complexity and costs along with benefits associated with each. Further assessment of the strategies with respect to each other is represented on three dimensions; benefits, complexity and costs of development and implementation (figure 2).

Thus, looking at the requirements and constraints and analyzing them in the light of the classification framework (figure 1) and evaluation of strategies employed to handle digital medical images (figure 2), three strategies emerge as potential solutions which meet some/all of the requirements/challenges listed above. These strategies are: Enterprise Computing, Grid Computing and Grid Services. Table 7 presents a comparison of the three potential strategies across the requirements and constraints identified by the stakeholders.

Table 7: Requirements and Corresponding Strategies

\begin{tabular}{|c|c|c|c|}
\hline \multirow[b]{2}{*}{ Requirements } & \multicolumn{3}{|c|}{ Support by Strategies } \\
\hline & $\begin{array}{c}\text { Enterprise } \\
\text { Computing } \\
\text { (EC) }\end{array}$ & $\begin{array}{c}\text { Grid } \\
\text { Computing } \\
(G C)\end{array}$ & $\begin{array}{c}\text { Grid } \\
\text { Services } \\
(G S)\end{array}$ \\
\hline $\begin{array}{l}\text { Virtual } \\
\text { Collaboration } \\
\text { of resources } \\
\text { across } \\
\text { hospitals }\end{array}$ & $\begin{array}{l}\text { Limited in } \\
\text { comparison to } \\
\text { GC and GS }\end{array}$ & $\begin{array}{l}\text { Higher than } \\
\text { EC and GS }\end{array}$ & $\begin{array}{l}\text { Higher } \\
\text { than EC }\end{array}$ \\
\hline $\begin{array}{l}\text { Resource } \\
\text { Sharing }\end{array}$ & Low & High & High \\
\hline High Security & Medium & High & High \\
\hline $\begin{array}{l}\text { Increased } \\
\text { efficiency }\end{array}$ & $\begin{array}{l}\text { Lower than GC } \\
\text { and GS with } \\
\text { regards to } \\
\text { efficient } \\
\text { handling of } \\
\text { resources }\end{array}$ & $\begin{array}{l}\text { Higher than } \\
\text { EC }\end{array}$ & $\begin{array}{l}\text { Higher } \\
\text { than EC }\end{array}$ \\
\hline $\begin{array}{l}\text { Large complex } \\
\text { analysis }\end{array}$ & $\begin{array}{l}\text { Limited } \\
\text { capacity to } \\
\text { handling } \\
\text { complex } \\
\text { analysis }\end{array}$ & $\begin{array}{l}\text { Higher than } \\
\text { EC and GS }\end{array}$ & $\begin{array}{l}\text { Higher } \\
\text { than EC }\end{array}$ \\
\hline Cost & $\begin{array}{l}\text { Lower than GC } \\
\text { and GS }\end{array}$ & $\begin{array}{l}\text { High } \\
\text { developmen } \\
\text {-t and } \\
\text { implementa- } \\
\text { tion but cost } \\
\text { saving in } \\
\text { resource } \\
\text { sharing }\end{array}$ & $\begin{array}{l}\text { Lower } \\
\text { developm } \\
\text { en-t and } \\
\text { implemen } \\
\text { ta-tion } \\
\text { but cost } \\
\text { incur in } \\
\text { fees paid }\end{array}$ \\
\hline Complexity & $\begin{array}{l}\text { Lower than GC } \\
\text { and GS }\end{array}$ & $\begin{array}{l}\text { Higher than } \\
\text { EC but } \\
\text { lower than } \\
\text { GS }\end{array}$ & High \\
\hline
\end{tabular}

By putting all the hospitals in partnership with hospital $\mathrm{ABC}$ on a grid, the requirement of resource sharing in a coordinated, controlled and secure fashion will be met. The development and implementation costs will be high 
but the complexity level stays below grid services. Grid computing also enables complex analysis on large datasets of medical images by controlled sharing of computational resources available on the grid thus increasing efficiency in resource usage across the hospitals on the grid.

Based on the assessment of strategies provided by the classification framework and detailed evaluation of each strategy in the preceding sections Grid Computing ranked better than the other potential strategies and was hence chosen as the strategy that was employed by the hospital.

\subsection{New Strategies}

The proliferation of digital medical images in the healthcare sector and the creation of virtual healthcare organizations which are capable of sharing resources in a coordinated secure manner have resulted in hospitals utilizing technology to meet the demands. The classification framework presented in the current research has proposed three main strategies that are currently used by the healthcare sector for storing, accessing, querying and analyzing medical images. This section presents examples of technologies that can be used in the context of medical images. As for their integration in the framework, they represent sub-strategies of distributed systems or of services-oriented systems.

\section{$>$ Knowledge \& Semantic Grid}

The Semantic Web, which is "an extension of the current Web in which information is given well defined meaning, better enabling computers and people to work in cooperation. It is the idea of having data on the Web defined and linked in a way that it can be used for more effective discovery, automation, integration, and reuse across various applications (...) data can be shared and processed by automated tools as well as by people" [51].

By adding the semantic web services to grid computing, the term "semantic grid services" has come to light [22]. In the context of grid services, the semantic web brings to the table a formal description of the service, thus fostering automated discovery and search, selection matching, composition and interoperation, invocation and execution monitoring [22]. This research advocates the use of semantic grid services to medical applications and more specifically to medical images. Some examples of work being done in the area of semantic grid services can be seen in the following references: [4]; [10]; [22]; [53].

\section{$>$ Federation of Grids}

It is a concept that hinges on using grid services to federate a collection of heterogeneous data bases for medical images analysis [4].

\section{$>$ Decision Support System and GDSS}

The usage of DSS and GDSS with Grid Services has been shown to improve efficiency and enable model integration, data collection, archiving and data mining along with coordinated and flexible resource sharing and data storage [37, 43]. Thus there is potential for using such strategies to improve the way medical images are handled.

\section{$>$ Query effectiveness}

An integrated medical system can answer queries such as: "Get all chest images of patients at the age of 20-30, that have blood type 'A' and are allergic to pine trees" [12]. However, the number of results can be quite enormous [38]. Therefore, this research encourages the use of Semantic web technologies in order to improve processing medical image content-based files.

Moreover, Cohen et al. [12] have already proved that it is possible to transform a DICOM file to XML-based HL7 Clinical Document Architecture standard. By obtaining an XML-based file, it is possible to index and compile medical images to the Electronic Health Record of the patient. Thus, information retrieval techniques can be used to increase query effectiveness.

\section{$>$ Wireless and mobile grid}

Wireless and mobile grid computing offer tremendous potential in the arena of medical image analysis. Wireless grids offer three novel elements in the field of grid computing [35]:

- New resources: along with processor power, disk space etc., wireless devices increasingly employ cameras, microphones, GPS receivers, an assortment of myriad interfaces (cell, radio, Wi-Fi and Bluetooth), and sensors. All these devices can supply additional data on temperature, health status etc.

- New places of use: wireless devices can reach remote geographical as well as social settings that computers have not traditionally penetrated.

- New institutional ownership and control patterns: Healthcare is inherently mobile and integrating wireless grids to wired grids allows doctors separated by time and space - to access and analyse medical image without being close to an infrastructure-based set-up.

Therefore, wireless grids have the potential of creating a network architecture that supports and pervades our lifestyle in incomprehensible ways [21]. 


\section{Conclusions}

The proliferation of information technologies in the medical field will unquestionable continue. Hence, it is essential to have a solid foundation, which clearly positions these technologies and their advantages and disadvantages. In this sense, based on a thorough literature review, this research proposes a framework that classifies strategies for working with digital medical images. This framework identifies various facets of problems associated with medical images, the issues that have yet to be dealt with by researchers, and how prior studies relate to each other and to the three-dimensional representation of the framework (e.g. figure 2).

The main contributions of this research are three fold. First, it provides an evaluation of the myriad of methods for storage, access and retrieval of digital medical images. In a way, it makes some sense of all the existing research while presenting the interrelationships among the three strategies. Second, the classification framework offers a well-structured view of the different challenges raised by working with medical images in context of each of the three strategies. Third, it provides guidelines for future research in this field with regard to the use of emergent technologies such as grid services and semantic web.

For researchers, this study identifies three practical strategies and points out future research directions. The framework can also be used to chart the prevalence of different types of healthcare imaging systems. For practitioners, the proposed framework might prove its usefulness by helping medical users develop a lucid understanding of the different approaches and of their advantages and disadvantages. Given the impact of the healthcare on the society's welfare, using one of the most recent strategies may provide easy and fast access to images stored across multiple institutions, improves the diagnosis process, and allows healthcare institutions to get access to specialists through remote consultations [34]. In terms of technologies, combining grid computing, web services and even semantic web will allow for complex computations and analysis of medical images in a more efficient manner. In addition, research in this direction will also open the door for using grid computing in commercial applications rather than merely for research or academic purposes [48]. Additional research in this area will further help increase the reliability and accuracy of the findings in the current research. First of all, the framework could be replicated through a survey of real healthcare imaging systems. Second, future research could also examine the vendor offerings and capabilities with respect to the proposed classification framework and to the requirements of healthcare facilities.

\section{Appendix A}

\begin{tabular}{|l|c|}
\hline \multicolumn{1}{|c|}{ Conference Proceedings } & Year \\
\hline $\begin{array}{l}\text { Proceedings of the 2nd International Workshop on } \\
\text { Grid Computing }\end{array}$ & 2001 \\
\hline Medical Imaging 2002 conference & 2002 \\
\hline Biogrid'03 in Proceedings of the IEEE CCGrid 2003 & 2003 \\
\hline Proceedings of PARCO2003 & 2003 \\
\hline Proceedings of SCI2003 & 2003 \\
\hline $\begin{array}{l}\text { Proceedings of the 2003 conference of the Centre for } \\
\text { Advanced Studies on Collaborative research }\end{array}$ & 2003 \\
\hline $\begin{array}{l}\text { 4th IEEE/ACM International Symposium on Cluster } \\
\text { Computing and the Grid (CCGrid 2004) }\end{array}$ & 2004 \\
\hline ACM Symposium on Applied Computing & 2004 \\
\hline $\begin{array}{l}\text { Proceedings of the 3rd International Conference on } \\
\text { Grid and Cooperative Computing (GCC 2004) }\end{array}$ & 2004 \\
\hline $\begin{array}{l}\text { Proceedings of the International Conference on } \\
\text { Information Technology: Computers and } \\
\text { Communications (ITCC03) }\end{array}$ & 2003 \\
\hline Proceedings of HealthGRID 2003 & 2003 \\
\hline Proceedings of HealthGRID 2004 & 2004 \\
\hline Proceedings of HealthGRID 2005 & 2005 \\
\hline
\end{tabular}

\begin{tabular}{|l|}
\hline \multicolumn{1}{|c|}{ Journals } \\
\hline Communications of the ACM \\
\hline Computer Methods and Programs in Biomedicine \\
\hline Computerized Medical Imaging and Graphics \\
\hline IBM Journal of Research and Development \\
\hline IBM Systems Journal \\
\hline Journal of Dermatology \\
\hline Journal of Digital Imaging \\
\hline Journal of Systems and Software \\
\hline Journal of the American Society for Information Science \\
\hline Methods of Information in Medicine \\
\hline Rapid Prototyping Journal \\
\hline
\end{tabular}

\section{References}

[1] Aloisio, G., Blasi, E., Cafaro, M., Fiore, S., Lezzi, D. and Mirto, M., Web Services for a Biomedical Imaging Portal. in Proceedings of the International Conference on Information Technology: Computers and Communications (ITCC.03), (Las Vegas, Nevada, 2003), IEEE press [Best student paper award], 432-437.

[2] Aloisio, G., Cafaro, M., Blasi, E., Fiore, S. and Mirto, M., A Grid Portal for Biomedical Imaging. in Proceedings of SCI2003, (Orlando, Florida, 2003), 57-62.

[3] Amendolia, S.R., Estrella, F., del Frate, C., Galvez, J., Hassan, W., Hauer, T., Manset, D., McClatchey, R., Odeh, M., Rogulin, D., Solomonides, T. and Warren, R. Deployment of a Grid-based Medical Imaging Application, Accepted by the 2005 HealthGrid Conference, 2005.

[4] Amendolia, S.R., Estrella, F., Hassan, W., Hauer, T., Manset, D., McClatchey, R., Rogulin, D. and Solomonides, T., MammoGrid: A Service Oriented Architecture based Medical Grid Application. in Lecture Notes in Computer Science, ((Proceedings of the 3rd International Conference on Grid and Cooperative Computing (GCC 2004). Wuhan, China. October 2004), 2004), 939. 
[5] Benkner, S., Engelbrecht, G., Backfrieder, W., Berti, G., Fingberg, J., Kohring, G., Schmidt, J.G., Middleton, S.E., Jones, D. and Fenner, J., Numerical Simulation for eHealth: Grid-enabled Medical Simulation Service. in Proceedings of PARCO2003, (Dresden, Germany, 2003).

[6] Bilykha, I., Bychkova, Y., Dahlema, D., Jahnkea, J.H., McCalluma, G., Obrya, C., Onabajoa, A. and Kuziemsky, C., Can GRID Services Provide Answers to the Challenges of National Health Information Sharing? in Proceedings of the 2003 conference of the Centre for Advanced Studies on Collaborative research, (Toronto, Canada, 2003), IBM Press, 39.

[7] Blackshaw, B.P. and Ellwood, J.R., Building distributed enterprise OLTP applications: current CORBA limitations. in First International Enterprise Distributed Object Computing Workshop (EDOC '97), (24-26 Oct 1997, 1997), 190-196.

[8] Breton, V., A.E.Solomonides and R.H.McClatchey, A perspective on the Healthgrid initiative. in 4th IEEE/ACM International Symposium on Cluster Computing and the Grid (CCGrid 2004), (Chicago USA, 2004).

[9] Breton, V., Medina, R. and Montagnat, J. DataGrid, Prototype of a Biomedical Grid. Methods of Information in Medicine, 2 (42), 2003, 143.

[10] Cannataro, M. and Talia, D. Semantics and Knowledge Grids: Building the Next-Generation Grid. IEEE Intelligent Systems, 19 (1), 2004, 56.

[11] Chiasson, M., Davidson, E., Kaplan, B., Kukafka, R. and Kuperman, G.J., Strangers in a Strange Land: Can IS Meet the Challenges and Opportunities of Research in Healthcare. in Proceedings of the Tenth Americas Conference in Information Systems (AMCIS), (Pittsburgh, 2004), Association for Information Systems.

[12] Cohen, S., Gilboa, F. and Shani, U., PACS And Electronic Health Records. in Medical Imaging 2002 conference, (San Diego, USA, 2002).

[13] DICOM. Digital Imaging and Communication in Medicine, National Electrical Manufacturers Association, 2004.

[14] Diepgen, T.L. and Eysenbach, G. Digital images in dermatology and the Dermatology Online Atlas on the World Wide Web. Journal of Dermatology, 25 (12), 1998, $782-787$

[15] Duque, H., Montagnat, J., Pierson, J.-M., Brunie, L. and Magnin, I.E., DM2: A Distributed Medical Data Manager for Grids. in Biogrid'03, proceedings of the IEEE CCGrid03, (Tokyo, Japan, 2003), 606.

[16] Elliot, P.J., Diedrichsen, J., Goodson, K.J., Riste-Smith, R. and Sivewright, G.J. An object-oriented system for 3D medical image analysis. IBM Systems Journal, 35 (1), 1996, 4.

[17] Estrella, F., Frate, C.d., Hauer, T., McClatchey, R., Odeh, M., Rogulin, D., Amendolia, S.R., Schottlander, D., Solomonides, T. and Warren, R., Resolving Clinical Queries across a Grid Infrastructure. in HealthGrid2004, (ClermontFerrand, France, 2004).

[18] Foster, I., Kesselman, C., Nick, J.M. and Tuecke, S. The Physiology of the Grid: An Open Grid Services architecture for Distributed Systems Integration, Open Grid Service Infrastructure WG, Global Grid Forum, June 22, 2002, 2002.
[19] Foster, I., Kesselman, C. and Tuecke, S. The Anatomy of the Grid: Enabling Scalable Virtual Organizations. International J. Supercomputer Applications, 15 (3), 2001.

[20] Fraser, M.D., Kumar, K. and Vaishnavi, V.K. Strategies for incorporating formal specifications in software development. Communications of the ACM, 37 (10), 1994, 74.

[21] Gaynor, M., Moulton, S.L., Welsh, M., LaCombe, E., Rowan, A. and Wynne, J. Integrating wireless sensor networks with the grid. IEEE Internet Computing, 8 (4), 2004, 32-39.

[22] Goble, C. and Roure, D.D. The Grid: An Application of the Semantic Web. SIGMOD, 31 (4), 2002, 65.

[23] Gomez, E.J., Quiles, J.A., Sanz, M.F. and Pozo, F.d. A User-Centered Cooperative Information System for Medical Imaging Diagnosis. Journal of the American Society for Information Science (JASIS), 49 (9), 1998, 810-816.

[24] Gottschalk, K., Graham, S., Kreger, H. and Snell, J. Introduction to Web services architecture. IBM Systems Journal, 41 (2), 2002, 170.

[25] Hacker, T.J. and Athey, B.D., A Methodology for Account Management in Grid Computing Environments. in Proceedings of the 2nd International Workshop on Grid Computing, (Denver, USA, 2001), Springer Verlag Press.

[26] Herveg, J., Crazzolara, F., Middleton, S.E., Marvin, D.J. and Poullet, Y., GEMSS: Privacy and security for a Medical Grid. in In Proceedings of HealthGRID 2004, (ClermontFerrand, France, 2004).

[27] Hevner, A.R., March, S.T. and Park, J. Design Science in Information Systems Research. MIS Quarterly, 28 (1), 2004, 75.

[28] Hieu, L.C., Bohez, E., Sloten, J.V., Phien, H.N. and al., e. Design for medical rapid prototyping of cranioplasty implants. Rapid Prototyping Journal, 9 (3), 2003, 175.

[29] Imielinska, C. and Molholt, P. Incorporating 3D virtual anatomy into the medical curriculum. Communications of the ACM, 48 (2), 2005, 49-54.

[30] Jones, D.M., Fenner, J.W., Berti, G., Kruggel, F., Mehrem, R.A., Backfrieder, W., Moore, R. and Geltmeier, A., The GEMSS Grid: An Evolving HPC Environment for Medical Applications. in HealthGRID 2004, (Clermont-Ferrand, France, 2004)

[31] Kallepalli, V.N., Ehikioya, S.A., Camorlinga, S. and Rueda, J.A. Security middleware infrastructure for DICOM images in health information systems. Journal of Digital Imaging, 16 (4), 2003, 356-364.

[32] Kaufman, A.E., Lakare, S., Kreeger, K. and Bitter, I. Virtual colonoscopy. Communications of the ACM, 48 (2), 2005, 37-41

[33] Kreger, H. Fulfilling the Web services promise. Communications of the ACM, 46 (6), 2003, 29.

[34] Laird, S.P., Wong, J.S., Schaller, W.J., Erickson, B.J. and Groen, P.C.d. Design and implementation of an Internetbased medical image viewing system. Journal of Systems and Software, 66 (2), 2003, 167-181.

[35] McKnight, L.W., Howison, J. and Bradner, S. Wireless Grids Distributed Resource Sharing by Mobile, Nomadic, and Fixed Devices. IEEE Internet Computing (Jul./Aug. 2004), 2004, 24. 
[36] Metaxas, D. Introduction to special issue on Medical image modeling tools and applications. Communications of the $A C M, 48$ (2), 2005, 26-29.

[37] Mineter, M.J., Skouloudis, A.N., Jarvis, C. and Dowers, S., Towards Utilisation of the Grid in Advanced Environmental Decision Support. in 8th Intern. Conference on Harmonisation with Dispersion Modelling for Regulatory Purposes, (Sofia, Bulgaria, 2002).

[38] Montagnat, J., Duque, H., Pierson, J.M., Breton, V., Brunie, L. and Magnin, I.E., Medical Image Content-Based Queries using the Grid. in HealthGrid'03, (Lyon, France, 2003), 138.

[39] Müller, H., Garcia, A., Vallée, J.-P. and Geissbuhler, A., Grid Computing at the University Hospitals of Geneva. in HealthGrid 2003, (Lyon, France, 2003).

[40] Müller, H., Rosset, A., Vallee, J.-P., Terrier, F. and Geissbuhler, A. A reference data set for the evaluation of medical image retrieval systems. Computerized Medical Imaging and Graphics, 28, 2004, 295-305.

[41] Ohbuchi, R., Miyazawa, T., Aono, M., Koide, A., Kimura, M. and Yoshida, R. Integrated medical-image system for cancer research and treatment. IBM Journal of Research and Development, 40 (2), 1996, 185-210.

[42] OMG. What is CORBA?, Object Management Group, 2005.

[43] Ong, M., Ren, X., Allan, J., Kadirkamanathan, V., Thompson, H.A. and Fleming, P.J. Decision support system on the grid. in Knowledge-Based Intelligent Information and Engineering Systems, 2004, 699-710.

[44] Park, K., Montillo, A., Metaxas, D. and Axel, L. Volumetric heart modeling and analysis. Communications of the ACM, 48 (2), 2005, 43-48.

[45] Power, D., Politou, E., Slaymaker, M., Harris, S. and Simpson, A., A relational approach to the capture of DICOM files for Grid-enabled medical imaging databases. in ACM Symposium on Applied Computing, (Nicosia, Cyprus, 2004).

[46] Rajendra Acharya, U., Niranjan, U.C., Iyengar, S.S., Kannathal, N. and Min, L.C. Simultaneous storage of patient information with medical images in the frequency domain. Computer Methods and Programs in Biomedicine, 76 (1), 2004, 13-19.

[47] Rogulin, D., Estrella, F., Hauer, T., McClatchey, R. and Solomonides, T. A Grid Information Infrastructure for Medical Image Analysis, 2004.

[48] Shankland, S. Fathers of grid computing form start-up, Tech Republic, 2004.

[49] Stal, M. Web services: Beyond component-based computing. Communications of the ACM, 45 (10), 2002, 71.

[50] Vaishnavi, V., Liegle, J. and Purao, S. Object-Oriented Product Metrics: A Generic Framework. Working Paper, CIS Department, Georgia State University, 2004.

[51] W3C. Semantic Web Activity Statement, World Wide Web Consortium, 2001.

[52] Yoo, T.S. and Ackerman, M.J. Open source software for medical image processing and visualization. Communications of the ACM, 48 (2), 2005, 55-59.

[53] Zhuge, H. China's E-Science Knowledge Grid Environment. IEEE Intelligent Systems, 19 (1), 2004, 13. 